\title{
Understanding evolution of product composition and volatility distribution through in-situ GC $\times$ GC analysis: a case study of longifolene ozonolysis
}

\author{
G. Isaacman ${ }^{1}$, D. R. Worton ${ }^{1,2}$, N. M. Kreisberg ${ }^{2}$, C. J. Hennigan ${ }^{3}$, A. P. Teng ${ }^{2}$, S. V. Hering ${ }^{2}$, A. L. Robinson ${ }^{3}$, \\ N. M. Donahue ${ }^{3}$, and A. H. Goldstein ${ }^{1}$ \\ ${ }^{1}$ Department of Environmental Science, Policy, \& Management, University of California, Berkeley, California, USA \\ ${ }^{2}$ Aerosol Dynamics, Inc., Berkeley, California, USA \\ ${ }^{3}$ Center for Atmospheric Particle Studies, Carnegie Mellon University, Pittsburgh, Pennsylvania, USA
}

Received: 4 December 2010 - Published in Atmos. Chem. Phys. Discuss.: 5 January 2011

Revised: 23 April 2011 - Accepted: 9 May 2011 - Published: 9 June 2011

\begin{abstract}
A method for predicting volatility and polarity based on chromatographic information was developed and applied to the smog chamber ozonolysis of the sesquiterpene longifolene. The products were collected and analyzed using a GC $\times$ GC Thermal Desorption Aerosol Gas Chromatograph/Mass Spectrometer (2D-TAG) and a quadrupole Aerodyne Aerosol Mass Spectrometer (AMS). All the secondary organic aerosol (SOA) was produced within the first half hour of the experiment. However, the oxidation level of the organic aerosol, as inferred from the fraction of ion $\mathrm{m} / \mathrm{z}$ 44 , suggested continued evolution of the SOA over the subsequent hours. Measurements of speciated organic compounds using 2D-TAG confirm that the composition of the particles changed over the course of the experiment. Nearly 200 oxidation products (thought to be mostly ketones and acids) were observed with 2D-TAG, but most could not be identified definitively due to a lack of standards and the absence of likely sesquiterpene oxidation products in available mass spectral databases. To categorize the observed products, the vapor pressure and oxygen-to-carbon ratio $(\mathrm{O} / \mathrm{C})$ of observed compounds were estimated based on their two-dimensional chromatographic retention times relative to those of known standards, establishing a retention time correlation (RTC) method for using 2D-TAG to better constrain important modelling parameters. The product distribution continuously evolved in volatility and oxygenation during $5 \mathrm{~h}$ of oxidation. Using peak area as the best available proxy for mass, we conclude that the product mixture includes many non-negligible products; the most abundant 3 compounds accounted for only half of the total observed peak area and $80 \%$ of peak area
\end{abstract}

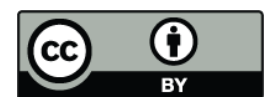

Correspondence to: G. Isaacman (gabriel.isaacman@berkeley.edu) was spread across 15 compounds. The data provide evidence for three conclusions: (1) 2D-TAG provides valuable volatility and oxygenation information even in the absence of definitive species identification, (2) complex particle-phase chemistry causes continued evolution of particle composition after new particles formation, and (3) minor products contribute significantly to SOA from the ozonolysis of longifolene.

\section{Introduction}

Atmospheric aerosols have been known for decades to have deleterious health effects (Pope and Dockery, 2006) and climate impacts (Intergovernmental Panel On Climate Change, 2007). Organic compounds comprise 20-90\% of submicron atmospheric aerosols (Kanakidou et al., 2005) of which a dominant fraction are estimated to form through the atmospheric processing of volatile organic compounds (VOCs) (Zhang et al., 2007). Biogenic VOCs (BVOCs), primarily isoprene $\left(\mathrm{C}_{5} \mathrm{H}_{8}\right)$, monoterpenes $\left(\mathrm{C}_{10} \mathrm{H}_{16}\right)$, and sesquiterpenes $\left(\mathrm{C}_{15} \mathrm{H}_{24}\right)$ account for approximately $90 \%$ of the estimated global VOC budget (Guenther et al., 1995), and more than half of all organic aerosol (OA) may come from the oxidation of these BVOCs (Hallquist et al., 2009). Significant uncertainty lies in the detailed composition of $\mathrm{OA}$ as well as the chemical mechanisms of oxidation and atmospheric processing that turn BVOCs into secondary organic aerosol (SOA). Recent findings have shown that on the order of $100 \mathrm{TgC}_{\text {year }}{ }^{-1}$ of sesquiterpenes may be emitted globally, accounting for approximately $10 \%$ of the global VOC budget (Ormeño et al., 2010). Oxidation products of many BVOCs, such as sesquiterpenes, likely remain unmeasured due to analytical constraints such as relatively low

Published by Copernicus Publications on behalf of the European Geosciences Union. 
volatility and high reactivity, but must contribute to SOA (Goldstein and Galbally, 2007). Sesquiterpenes tend to have much higher SOA yields (typically $\sim 70 \%$ or higher) than monoterpenes (mostly under 40\%) (Lee et al., 2006a, b; $\mathrm{Ng}$ et al., 2007) because of their high molecular mass and low-volatility and have been shown to nucleate new particle growth far more efficiently than monoterpenes (Bonn and Moortgat, 2003). These findings taken together suggest sesquiterpenes are likely significant precursors of OA and warrant further study.

Many smog chamber studies have focused on the products of sesquiterpene and monoterpene ozonolysis (Bonn and Moortgat, 2002, 2003; Donahue et al., 2005; Lee et al., 2006a; Zhang et al., 2006; Donahue et al., 2007; Maksymiuk et al., 2009) but due to instrument limitations, compound specific analysis of the particle phase is infrequently conducted. Studies that have identified individual compounds in the particle phase (Gao et al., 2004; Jaoui et al., 2008; Surratt et al., 2008; Claeys et al., 2009; Winterhalter et al., 2009) rely on filter collection, typically limiting analysis to one sample per experiment. By using the GC $\times$ GC Thermal Desorption Aerosol Gas Chromatograph/Time-of-Flight Mass Spectrometer (2D-TAG) (Worton et al., 2011), this study is the first attempt, that we know of, to understand the change in SOA composition from a single BVOC precursor over time.

Longifolene is one of the dominant sesquiterpenes emitted from ponderosa pine forests (Bouvier-Brown et al., 2009); it is also emitted in small amounts from agricultural crops (Ormeño et al., 2010). Furthermore, it is a good surrogate compound for the study of sesquiterpene oxidation because, unlike other sesquiterpenes which contain multiple double bonds, it contains only a single exocyclic double bond, potentially simplifying the expected oxidation chemistry and product mixture. As an atmospherically relevant compound with a simpler reaction pathway than other sesquiterpenes, ozonolysis of longifolene is employed in this work as a useful model compound for the study of sesquiterpene oxidation.

Having only one reaction site for ozone, the initial step should be limited to formation of a primary ozonide (POZ) through addition of ozone to longifolene (labeled as species "1" in Fig. 1) across the double bond (Winterhalter et al., 2000; Atkinson and Arey, 2003; Nguyen et al., 2009). The $\mathrm{POZ}$ then splits to form either longicamphenylone (species " 2 " in Fig. 1) or a Criegee Intermediate (CI). In general, POZ decomposition favors the more substituted $\mathrm{CI}$, suggesting the reaction should proceed preferentially down the lower branch in Fig. 1. If stabilized, the CI may react with a ketone to yield a variety of secondary ozonides (SOZ) - potentially including a dimer $\mathrm{SOZ}$ - that would likely contribute to the nucleation of new particles because of the rapid decrease in volatility accompanying this increase in molecular weight (Bonn et al., 2002). However, the stabilization of the excited CI competes with unimolecular reactions and complex radical chemistry and the branching between these available pathways is a matter of active debate (Chuong et al., 2004). Consequently,

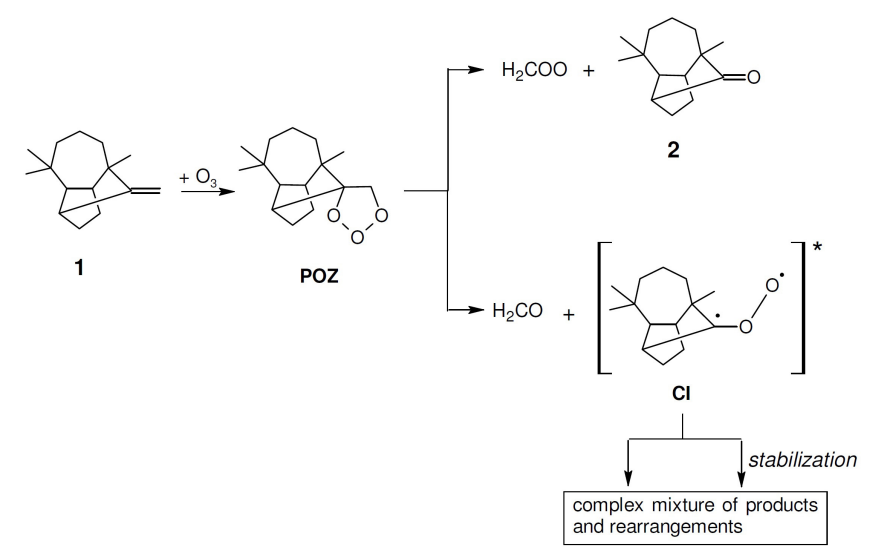

Fig. 1. Theoretical initial ozonolysis reaction pathway for longifolene (1) based on work on $\beta$-pinene by Nguyen et al. (2009).

the role of SOZs in the SOA formation from BVOCs is still uncertain, though direct measurements of the product mixture composition may be a valuable tool in understanding the mechanisms.

An excellent and extensive modeling treatment of $\beta$ pinene ozonolysis, a monoterpene containing a bridge and a single exocyclic double bond, like longifolene, can be found in Nguyen et al. (2009). The ketone formation pathway leading to compound 2 in Fig. 1 is expected in $5-20 \%$ yield in the oxidation $\beta$-pinene and is therefore likely to have a similar yield in the longifolene system (Winterhalter et al., 2000; Nguyen et al., 2009). A similar yield of the ketone product is seen for the exocyclic double bond in limonene ozonolysis (Maksymiuk et al., 2009). This reaction pathway proceeds to generate a very complex mixture of products, with at least 7 stable products identified by Nguyen et al. (2009). Aumont et al. (2005) estimate that a $C_{15}$ alkane may form on the order of $10^{10}$ to $10^{11}$ compounds after only a few generations, though the contribution of most of these to the overall mass balance is likely to be negligibly small.

Owing to the complexity of VOC oxidation, models are typically simplified by binning oxidation products based on volatility in order to assess their potential in SOA formation. In the commonly used "two-product model" (Odum et al., 1996), SOA yields are modeled using two surrogate compounds that reproduce the partitioning behavior of the mixture as measured in a smog chamber, essentially separating a subset of the product mixture into largely gas-phase and largely aerosol-phase products. This has recently been expanded into a multi-product model that includes oligomerization and uses polarity as a parameter in a addition to volatility (Pankow and Barsanti, 2009). A similar model has been developed by Donahue et al. (2006), in which compounds are grouped into multiple volatility bins that span the gas and condensed phases. This "volatility basis set" (VBS) model accounts for changes in gas-particle partitioning through multiple generations of oxidation by transferring 
mass between volatility bins. Compound specific identification is unnecessary for these models as long as the volatility distribution of these compounds can be deduced. The VBS model has recently been expanded into a two-dimensional model (2D-VBS) that includes oxygen to carbon ratio $(\mathrm{O} / \mathrm{C})$ as a parameter to better understand the thermodynamics and mixing of organic aerosol and to better constrain its atmospheric evolution (Jimenez et al., 2009; Donahue et al., 2011). This allows the thermodynamics and partitioning of these complex mixtures to be modeled in the context of solvent-species interactions (i.e. oxygenated compounds are less likely to condense onto non-oxygenated aerosol). That both of these frameworks - multi-product models and volatility basis sets - have recently been modified to include a polarity parameter is indicative of the role that oxygenation plays in determining partitioning and SOA formation.

The complexity of organic aerosol makes measurement of products and processes difficult even in simpler scenarios such as longifolene ozonolysis. Bulk analysis - such as with an Aerodyne Aerosol Mass Spectrometer (AMS) - provides the total submicron organic-aerosol mass and some information about average chemical properties. This yields significant insight but often does not provide enough detail on volatility distribution for use in the models described above. An alternate approach is to identify and measure a few useful tracer compounds that provide information about sources or processes. This is, in most cases, a "chromatographic approach", which uses liquid or gas chromatography to separate and speciate complex mixtures to find and apply these tracers. It is the approach for which TAG and 2D-TAG were designed; their high time-resolution allows for detailed analysis of tracer correlation and covariance that can be used to determine the various sources of OA (Williams et al., 2010b). However, ambient aerosol contains thousands of compounds, so comprehensive knowledge of the composition is unattainable. Consequently, chromatographic based techniques provide high levels of detail but not enough bulk information to be useful in models. Therefore, neither the bulk approach nor the chromatographic approach can satisfy all the data needs of the new modeling frameworks.

This work seeks to expand the chromatographic methods by empirically binning compounds based on volatility and polarity, even in the absence of compound identification. Chromatography is limited as to its application for bulk analysis because of difficulties in eluting very polar compounds and thermal decomposition of some compounds (e.g., oligomers). Therefore, this work does not attempt a mass balance nor make claims on the full mass-based volatility distribution. Nevertheless, this method provides insight into the complexity of these systems.

This study lays the groundwork for using a chromatographic approach to place complex atmospheric mixtures into the volatility-polarity models discussed above. This is achieved by correlating retention time to chemical properties. Applying this retention time correlation (RTC) method to 2D-TAG data - an instrument with fairly high time resolution - allows the study of complex condensed-phase product mixtures as their distribution in the volatility-polarity plane changes. In this work, the method developed is applied to SOA formed from longifolene ozonolysis in a smog chamber. Polarity and volatility of the products observed are placed qualitatively into the 2D-VBS framework as a demonstration of the utility of the RTC method. The data are then used to investigate the evolution of the products. As 2D-TAG quantitation capabilities improve, RTC may be used to quantitatively inform these models.

\section{Experimental}

\subsection{Experimental set-up}

The experiment was performed in the Carnegie Mellon University smog chamber using a $10 \mathrm{~m}^{3}$ Teflon reactor (Welch Fluorocarbons). Longifolene (56 ppb, Fluka, purity $\geq 99 \%$ )) was added by flash vaporization. The reaction was carried out under dry conditions $(<10 \% \mathrm{RH})$ at a constant temperature of $20^{\circ} \mathrm{C}$. The experiment was carried out in the dark with polydisperse seed aerosol, generated by nebulizing $7 \mathrm{M}$ $\left(0.9 \mathrm{~g}^{-1}\right)$ ammonium sulfate aqueous solution. An excess of ozone $(\sim 1600 \mathrm{ppb})$ produced from an ozone generator (Azco HTU500ACPS) was added one hour after the addition of seed aerosol and was continuously monitored using an ozone analyzer (Dasibi 1008-PC). The relatively high ozone concentration was necessary because of the relatively low reactivity of the exocyclic double bond in longifolene (Shu and Atkinson, 1994; Atkinson and Arey, 2003). The evolution of the resultant aerosol was continuously measured using a scanning mobility particle sizer (SPMS, TSI 3936) and a quadrupole AMS (Q-AMS, Aerodyne Research Inc.). The AMS data were analyzed using the standard fragmentation and batch tables reported by Allan et al. (2004).

Four "snapshot" samples were collected and analyzed by 2D-TAG for condensed phase speciated organics during the experiment. TAG is a custom built in-situ gas chromatograph, originally described by Williams et al. (2006); incorporation of GCxGC separation into TAG (2D-TAG) is described by Goldstein et al. (2008) and Worton et al. (2011). Air is sampled at $91 \mathrm{pm}$ and the particles are humidified and impacted onto a passivated metal surface in a customdesigned collection and thermal desorption cell. This cell is heated to $300^{\circ} \mathrm{C}$ under helium flow and the sample analyzed by a gas chromatograph (Agilent 6890) coupled to an electron impact (EI) time-of-flight mass spectrometer (SAI Kronus ToF-MS). During analysis, the subsequent sample is collected, allowing semi-continuous sampling that is only limited by the length of the chromatographic separation program ( $2 \mathrm{~h}$ in this work).

The TAG sample schedule is shown in Fig. 2. TAG \#1 was collected $35 \mathrm{~min}$ after the addition of the seed aerosol 


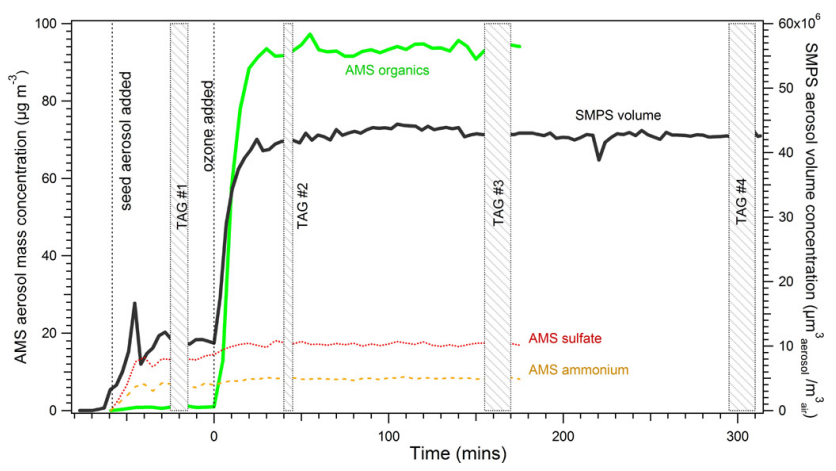

Fig. 2. Wall-loss corrected aerosol mass and volume concentrations as measured by the AMS and SMPS, respectively.

and $15 \mathrm{~min}$ before ozone addition. The other samples (TAG \#2, \#3 and \#4) were collected between 40-45, 155-170 and 295-310 min after ozone addition, respectively. The first two samples (TAG \#1 and \#2) were collected for 10 and $5 \mathrm{~min}$ (sample size $0.09 \mathrm{~m}^{3}$ and $0.05 \mathrm{~m}^{3}$, respectively) and the latter two samples (TAG \#3 and \#4) for $15 \mathrm{~min}$ (sample size $\left.0.14 \mathrm{~m}^{3}\right)$.

Collection efficiency is very high for particles larger than approximately $80 \mathrm{~nm}$ (Williams et al., 2006). Elution through the chromatographic columns is generally limited to compounds with an $\mathrm{O} / \mathrm{C}$ of 0.30 or less, though some compounds have been observed by TAG that have an $\mathrm{O} / \mathrm{C}$ of up to 0.6 (Williams et al., 2010a). Compound identification is performed by comparison of collected EI spectra to the National Institute of Standards and Technology Mass Spectral Library.

\subsection{Wall loss correction of AMS and SMPS data}

Wall loss correction was performed using the extrapolation method published by Pathak et al. (2007). Briefly, wall loss is assumed to be the dominant factor in the change in mass concentration at the end of the experiment, which allows a wall loss rate to be empirically derived and applied throughout the experiment. As wall-loss rates are size dependent (Pierce et al., 2008), the extrapolation method was applied in two ways: (1) calculating and applying size-dependent wall loss rates for each AMS and SMPS size bin, and (2) calculating and applying a single size-independent wall loss rate. However, calculations of the total mass and volume concentrations gave similar results using these two methods, so, for simplification, values shown are calculated using the sizeindependent wall loss correction method.

\section{Development of new methodology}

Categorizing unidentified compounds can be achieved through comprehensive two-dimensional chromatography, which provides separations based on chemical properties, most commonly volatility and polarity. This empirically maps the distribution of complex mixtures across a twodimensional space. Consequently, it should be possible to extract from chromatographic data the chemical properties necessary to place compounds in any of the two-dimensional modeling frameworks discussed above.

In order to parameterize volatility and polarity, the twodimensional chromatographic plane was mapped using a two-dimensional planar fit of $\mathrm{O} / \mathrm{C}$ and volatility derived from 2D-TAG analysis of known compounds with functionalities similar to those expected from the oxidation of a sesquiterpene (ketones, acids, esters, etc.). Unknown compounds were then assigned an estimated value for these properties based on where they fall in this two-dimensional plane. The columns used by 2D-TAG have been optimized for the separation of atmospheric constituents - the first dimension of 2D-TAG is primarily a volatility separation (Restek Rxi-5ms) while the second dimension separates compounds primarily by polarity (Restek Rtx-200), which is at least partially a function of the $\mathrm{O} / \mathrm{C}$ (Worton et al., 2011). Therefore the first and second dimension retention times $\left(t_{R}^{1}\right.$ and $t_{R}^{2}$, respectively), provide information on volatility and oxygenation, thus providing information on chemical properties that are useful for the modeling frameworks discussed above. This retention time correlation (RTC) method is applied here using volatility and polarity separation, but a different column set could be used that separates based on different properties, extending the utility of this method.

We characterized the chromatographic plane by analyzing a standard mixture of 25 known compounds commonly found in ambient aerosols, as well as 10 confidently identified compounds observed in ambient data; these compounds are listed in the supplementary information. The vapor pressures, $v_{P}$, of these 35 aliphatic compounds with various functionality and known retention times were calculated using the US Environmental Protection Agency Estimation Programs Interface (EPI) Suite (US EPA, 2008), which is based on a group contribution method (specifically a modified Grain method, see Lyman (1985) for more details). The calibration compounds include most functionalities commonly observed in atmospheric organic aerosols and were selected to span as much of the 2D-TAG plane as possible given the suite of known standards injected. Using a planar fit to these known compounds (Fig. 3a), retention times can be converted into approximate vapor pressures for any aliphatic compound. A similar correlation technique has been used for decades and has been shown in previous studies to be effective within acceptable error using only a single dimension retention time (Jensen and Schall, 1966; Hinckley et al., 1990). In this work we are extending these ideas to include a second dimension. It is clear from the retention times of known compounds that $t_{R}^{2}$ is not entirely independent of vapor pressure in the 2DTAG system, highlighting the importance of including the second dimension. 

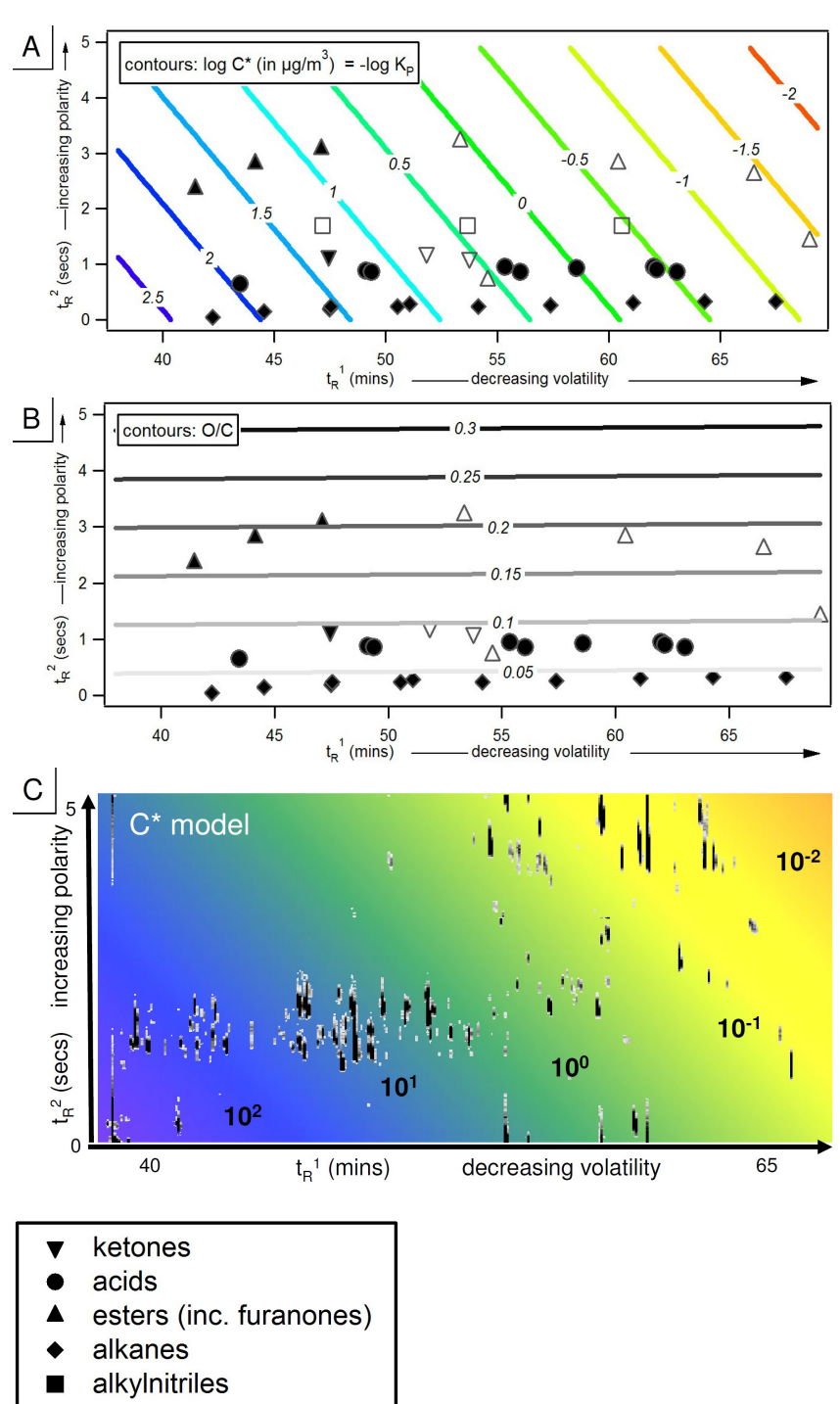

Fig. 3. (A) Effective saturation concentration $C^{*}$-fit based on known compounds. (B) O/C-fit based on known compounds. (C) $C^{*}$-fit applied to TAG \#3: color scale matches (A) above. Filled markers are standard compounds, open markers are confidently identified in ambient data. Compounds represent classes relevant to ambient aerosols and are listed in full in the Supplementary Information.

The planar $v_{P}$-fit reproduces the vapor pressure of a compound within half an order of magnitude of the calculated value for known compounds, which is within the approximate error of the group contribution methods (Pankow and Asher, 2008; US EPA, 2008). The EPI method was selected for vapor pressure calculations as it yields a better empirical planar fit than SIMPOL (Pankow and Asher, 2008), the group contribution method used in recent VBS work (Donahue et al., 2011). For more information on the EPI and SIMPOL fits to these compounds, see the supplementary information. Use of one vapor pressure estimation method over another will likely somewhat shift the dependence on $t_{R}^{2}$ but is unlikely to have a significant effect on the results described here. As the use of 2D-TAG increases, more aliphatic compounds in this volatility range will be definitively identified and the fit shown in Fig. 3a will be better constrained.

Calculated vapor pressures have been converted to effective saturation concentration, $C^{*}$, which has been widely adopted by the atmospheric chemistry community and allows data to be placed in the VBS framework (Donahue et al., 2006). The $C^{*}$ of a compound is the aerosol loading $\left(\mathrm{C}_{\mathrm{OA}}\right)$ necessary to cause the condensation of $50 \%$ of the mass of the compound. It is the inverse of the partitioning coefficient, $K_{p, i}$, as defined by Pankow (1994), calculated as:

$$
C^{*}=\frac{1}{K_{p, i}}=\frac{\mathrm{MW}_{i} 10^{6} \zeta_{i} v_{P, i}}{760 R T}
$$

where $\mathrm{MW}_{i}$ is the molecular weight of species $i\left(\mathrm{~g} \mathrm{~mol}^{-1}\right)$, $\zeta_{i}$ is an activity coefficient of species $i$ that parameterizes non-ideal behavior of a species, $v_{P, i}$ is the saturation vapor pressure of species $i$ (Torr), $R$ is the ideal gas constant, and $T$ is temperature (K). Because the fit will be applied to unknown compounds, bulk values must be chosen for $\zeta_{i}$ and $\mathrm{MW}_{i}$. Much of the uncertainty in this calculation comes from $\zeta_{i}$, which is not well understood and can vary by orders of magnitude depending on species $i$ (Williams et al., 2010a), so as in previous work (Donahue et al., 2006), a value of 1 (pseudo-ideal behavior) is selected here as an approximation. For $\mathrm{MW}_{i}$, a value of $200 \mathrm{~g} \mathrm{~mol}^{-1}$ is commonly used and is close to the average molecular weight for compounds observed by TAG (Barsanti and Pankow, 2004; Williams et al., 2010a). Though this value is likely $10-20 \%$ lower than the actual average molecular weight of aerosol formed by longifolene $\left(\mathrm{MW}=204 \mathrm{~g} \mathrm{~mol}^{-1}\right)$, this error is small in comparison to uncertainty in $\zeta_{i}$. Therefore $\mathrm{MW}_{i}=200 \mathrm{~g} \mathrm{~mol}^{-1}$ has been used to be consistent with previous work. The $C^{*}$-fit allows the partitioning, and therefore the SOA forming potential, of unknown compounds to be inferred using 2D-TAG data.

$\mathrm{O} / \mathrm{C}$ can be predicted using the same basic approach. A planar fit of $\mathrm{O} / \mathrm{C}$ as a function of retention time for 32 known compounds (compounds that contain heteroatoms other than oxygen, specifically the three alkylnitriles, are excluded from this fit) shows that $\mathrm{O} / \mathrm{C}$ is nearly independent of $t_{R}^{1}$ and strongly correlates with $t_{R}^{2}$ in the case of aliphatic compounds (Fig. 3b). This O/C-fit allows prediction of the level of oxygenation based on retention times without requiring knowledge of the exact functionality of a given compound - potentially useful information in understanding the age and sources of unknown compounds.

Figure $3 \mathrm{c}$ shows an example application of the $C^{*}$-fit to TAG \#3 using the same color scale for $C^{*}$ values as Fig. 3a. (Figs. 3 and 8 are shown using data from TAG \#3, when most peaks have been formed but wall loss is less significant than in TAG \#4). One challenge is that, to date, no definitively identified aliphatic compounds in $2 \mathrm{D}-\mathrm{TAG}$ standard or 
ambient data have $t_{R}^{2}$ values greater than $3 \mathrm{~s}$. Therefore, in order to apply the RTC method to all observed peaks, the fit was linearly extrapolated to values of $t_{R}^{2}$ up to $5 \mathrm{~s}$. This extrapolation unavoidably increases uncertainty, but relative standard deviation of the slope of this fit - a measure of the uncertainty in this method - is less than $20 \%$ and will be increasingly well-constrained as identification efforts improve and 2D-TAG becomes more widely applied.

Applying both the $C^{*}$ - and $\mathrm{O} / \mathrm{C}$-fits derived from the standard mixture allows 2D-TAG data to be placed into the 2DVBS. The same approach could be used for other proposed two-dimensional spaces such as the ones from Pankow and Barsanti (2009), who propose a number of options for quantifying polarity that may be more precise than a simple $\mathrm{O} / \mathrm{C}$. Other measures of polarity can be estimated by deriving appropriate fits to $t_{R}^{2}$, so the RTC method can be used to place aerosol composition into any of the recently proposed volatility-polarity planes that may form the basis of the next generation of model frameworks. Such frameworks cannot yet be quantitatively applied to these data, but ozonolysis of longifolene serves as a qualitative example in which observed peak area is used as the best available proxy for mass.

\section{Results and discussion}

\subsection{Aerosol concentration and size distribution}

Figure 2 shows time series of wall loss corrected AMS and SMPS data. The high ozone concentration caused the reaction to proceed quickly; particle formation occurred almost entirely in the first $30 \mathrm{~min}$ after ozone addition (which occurs at $t=0$ in all figures). After this rapid formation, the wall loss corrected aerosol mass and volume concentrations as measured by the AMS and SMPS, respectively, remained stable for the remainder of the experiment. The ratio of organics to sulfate from the AMS also remained relatively stable after this initial formation, supporting the conclusion that organic particle formation has ceased. All particle formation therefore occurred before TAG \#2 was collected and aerosol mass, once corrected for wall loss, remained unchanged during the subsequent TAG samples (TAG \#3 and \#4). This allows us to study the evolution of particle composition over approximately five hours.

The size distribution of the aerosol is bimodal and remained largely unchanged after particle formation ends. The size distribution during TAG \#2 is shown in Fig. 4 without correcting for wall loss to avoid potential size dependent artifacts of the wall loss correction process. The peak in the size distribution at $200-300 \mathrm{~nm}$ is expected as organic compounds condense onto the ammonium sulfate seed aerosol, which is mostly in that size range (red and yellow dashed lines in Fig. 4). However, the prominent peak at smaller diameters (centered at $90 \mathrm{~nm}$ ) - where there is no seed aerosol - indicates substantial particle nucleation and growth. This

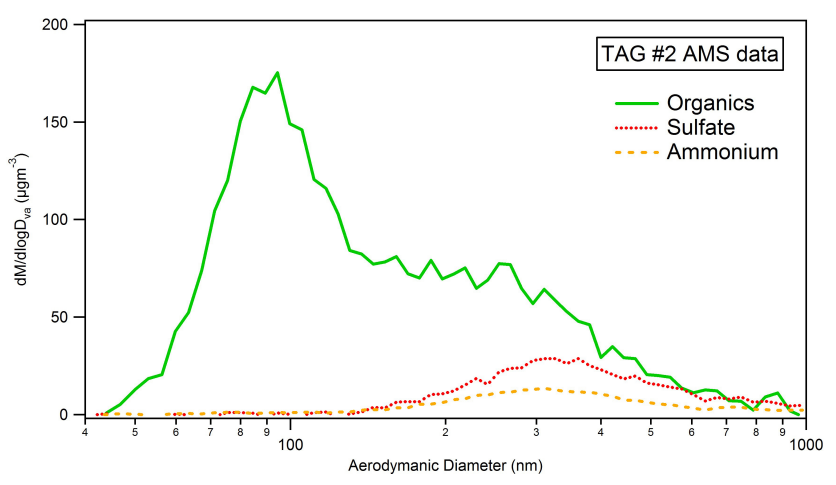

Fig. 4. Average AMS particle size distribution during TAG \#2, collected 40 to $45 \mathrm{~min}$ after the addition of ozone. These data have not been wall loss corrected in order to avoid artifacts potentially introduced in the correction process.

homogenous nucleation of particles by organic compounds requires the rapid production of organic compounds with very low vapor pressures. However, homogenous nucleation may be caused here by the very rapid particle growth caused by the high concentration of ozone and may not be atmospherically relevant.

\subsection{Evolution of the product mixture}

\subsubsection{Increasing oxidation level}

Though particle formation and mass growth reached completion quickly, AMS data show some evidence for the continued evolution of products. The fraction of organic aerosol comprised of ion $m / z, 44$ as obtained by the AMS $\left(f_{44}\right)$ can be used to estimate the $\mathrm{O} / \mathrm{C}$ of the aerosol (Aiken et al., 2008) - because $\mathrm{m} / \mathrm{z} 44$ comes primarily from $\mathrm{CO}_{2}^{+}$, high $f_{44}$ is indicative of more oxidized aerosol. Figure 5 shows the evolution of $f_{44}$ throughout the period of the experiment for which AMS data are available. When particle formation begins, $f_{44}$ is high due to the partitioning into the particle phase of highly oxygenated, and therefore less volatile, compounds (Kroll and Seinfeld, 2008). As aerosol loading increases, $f_{44}$ decreases because more volatile, less oxygenated compounds partition into the particle phase (Odum et al., 1996; Donahue et al., 2006). Although production of new particle mass appears to stop after 30 minutes, $f_{44}$ increases throughout the experiment. Particles are lost to the walls as the experiment progresses but are thought to continue to participate in partitioning (Weitkamp et al., 2007), so this slow but continuous increase in $f_{44}$ is unlikely to be entirely an artifact of partitioning, indicating a slow increase in particle oxidation level. Estimated O/C increases from 0.24 about 20 min after ozone was added to $\mathrm{O} / \mathrm{C}$ of 0.30 after three hours of ozone exposure.

This increase in oxygenation suggests either heterogeneous processing or complex partitioning-oxidation interactions where semi-volatile particle-phase products evaporate, 


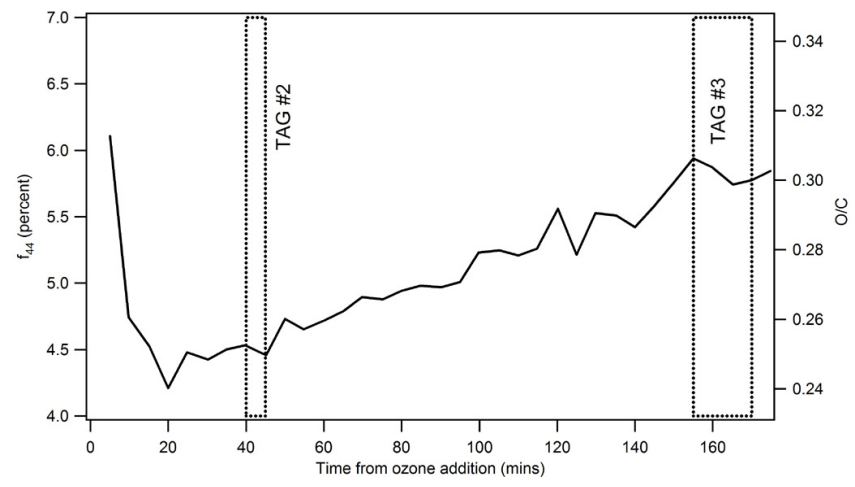

Fig. 5. Percentage of organic aerosol comprised of $m / z, 44\left(f_{44}\right)$ over the course of the longifolene ozonolysis. $\mathrm{O} / \mathrm{C}$ is estimated from this value using the correlation reported by Aiken et al. (2008).

oxidize in the gas-phase, and re-condense. Although the continued oxidation of the condensed phase is common in smog chamber experiments, the oxidant in this case is unclear - the oxidation products of longifolene are not expected to have double bonds that would react with ozone. However, due to the absence of an $\mathrm{OH}$ scrubber and the presence of small amounts of water vapor in the chamber, it is possible that some hydroxyl radical chemistry occurs, creating a complex chemical mixture that may continue to oxidize through hydration and/or dehydration reactions. These reaction pathways are speculative, but the continued increase in $f_{44}$ suggests the presence of complex oxidation chemistry, a conclusion supported by increasing complexity and oxygenation of 2D-TAG samples throughout the experiment.

\subsubsection{Continued functionalization and increasing complexity}

Though TAG \#2 was collected immediately following particle formation, and TAG \#3 and \#4 were collected later in the experiment, wall loss corrected aerosol concentrations were stable across all three samples (Fig. 2). Owing to the relatively low $\mathrm{O} / \mathrm{C}$ of the product mixture $(<0.30)$, most of the particle-phase product should elute through the TAG columns.

Only three likely products of longifolene oxidation are included in available mass spectral libraries, so the vast majority of the observed peaks could not be specifically identified. It was therefore useful to apply the RTC method to categorize and understand the chemical properties of these unidentified products. The $C^{*}$ - and $\mathrm{O} / \mathrm{C}$-fits described above were applied to TAG \#2, TAG \#3, and TAG \#4 to provide insight into the chemical and volatility evolution of the condensed phase mixture produced through ozonolysis of longifolene.

The number of peaks in each volatility bin, as well as the accompanying chromatograms for each snapshot are shown in Fig. 6. Any peak in the most volatile $C^{*}$ bin $\left(10^{3} \mu \mathrm{g} \mathrm{m}^{-3}\right)$ has been neglected because this volatility bin would include

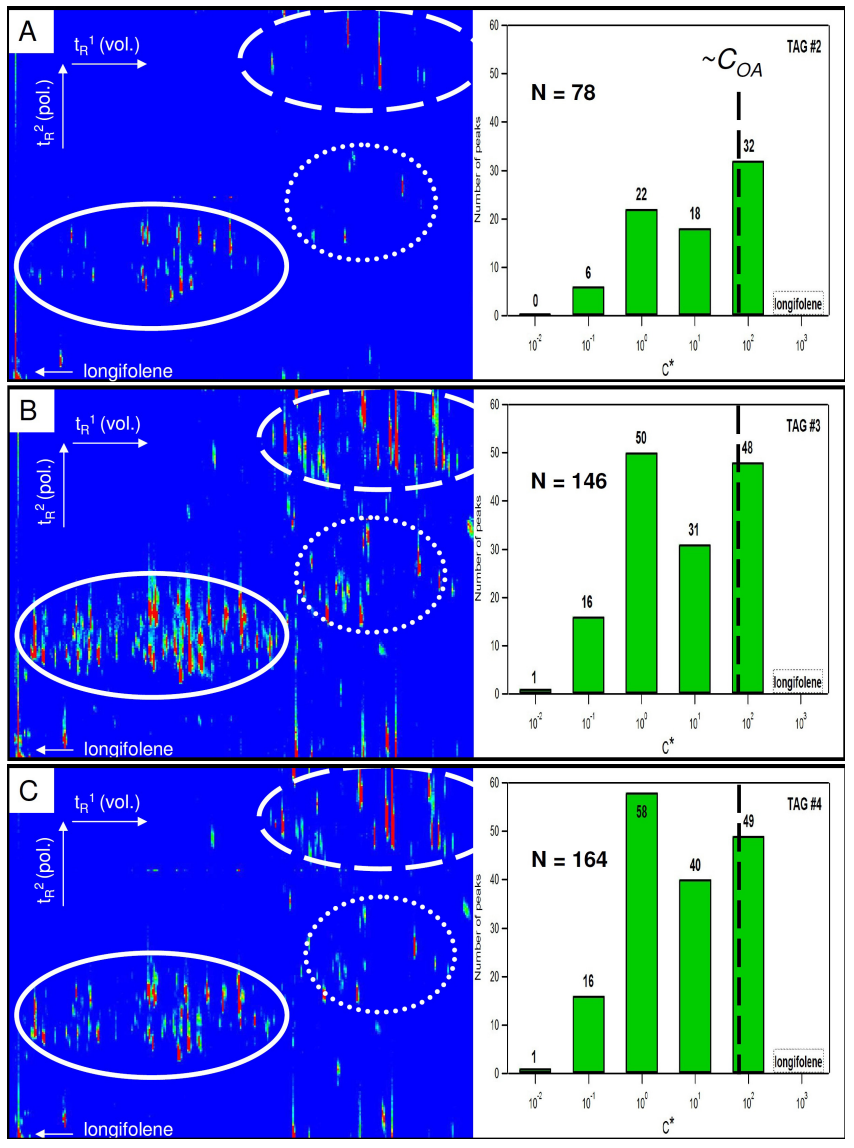

Fig. 6. GC $\times$ GC chromatograms and the number of peaks in each $C^{*}$ bin in samples (A) TAG \#2; (B) TAG \#3; and (C) TAG \#4. The $\mathrm{X}$ - and y-axes are $t_{R}^{1}$ (volatility separation) and $t_{R}^{2}$ (polarity separation), respectively, and have the same scale as Fig. 3 (approximately 40 to $65 \mathrm{~min}$ for $t_{R}^{1}$ and 0 to $5 \mathrm{~s}$ for $t_{R}^{2}$ ). Color indicates detector response (total ion chromatogram) in arbitrary units (blue is lowest, red is highest). Circled Region 1 (solid line) contains less oxygenated, more volatile compounds while peaks in Regions 2 (dotted line) and 3 (dashed line) are thought to be more oxygenated, less volatile compounds and are discussed in detail in Section 3.2 of this text. Number of compounds in each $C^{*}$ volatility bin is given on the right along with the total number of observed peaks. Aerosol mass concentration is shown as the line at $\mathrm{C}_{\mathrm{OA}}$.

compounds not collected by 2D-TAG, making the number of peaks in this bin unknown. In TAG \#2, immediately following particle formation, 78 peaks are observed. This increases to 146 peaks in TAG \#3 and 164 peaks in TAG \#4. The product longicamphenylone (Fig. 1, compound 2), could not be definitively identified though longifolenaldehyde is thought to have been identified.

While the number of peaks grows in every volatility bin between these samples, the overall peak distribution shifts toward less volatile bins over the course of the experiment. For example, in the first sample, TAG \#2, most of the products - including the peak thought be longifolenaldehyde - 
are in the more volatile, less polar Region 1 (Fig. 6, solid circle). Based on their location in the two-dimensional plane, these compounds are likely to be the result of single oxygen addition such as ketones or aldehydes. There are a few large peaks, however, in the low volatility, oxygenated Region 3 (Fig. 6, dashed circle) that may be the products responsible for homogenous nucleation. Regions 2 (Fig. 6, dotted circle) and 3 in this early sample contain relatively few peaks. However, as the experiment progresses, the number of peaks in these regions increases significantly, indicating an aerosol of increasing complexity and increasing oxygenation; peaks in these regions are likely to be products of the addition of multiple oxygen atoms, potentially multi-functional acids or esters formed through multiple generations of oxidation. In addition to a few large peaks, Regions 2 and 3 contain many small peaks that account for only $10-20 \%$ of the aggregate total peak area because the exponential increase in the number of potential products with each generation distributes the mass over many compounds. It should be noted here that more oxygenated compounds typically exhibit electron impact response factors that are an order of magnitude smaller than those of saturated hydrocarbons, suggesting that using peak area as a proxy underestimates the mass contribution from these compound; the use of peak area in this work is meant for qualitative comparison.

The distribution of peaks across these regions is shown in the framework of the 2D-VBS in Fig. 7. A few large, lowvolatility peaks are observed in TAG \#2 that are likely the products responsible for homogeneous nucleation, but most of the peaks observed in TAG \#2 are in the higher volatility, less oxygenated region. Between TAG \#2 and TAG \#3, the number of peaks nearly doubles, with many of these new peaks in the regions of lower volatility and increased $\mathrm{O} / \mathrm{C}$. This increase in complexity includes the apparent formation of a few larger peaks that each account for a few percent of the total peak area. While the higher volatility, less oxygenated region does change, peaks in this region primarily shrink in relative size and most of the newly formed peaks are negligible. The shift of the peak distribution up (higher $\mathrm{O} / \mathrm{C}$ ) and to the left (lower volatility) in 2D-VBS space suggests continued functionalization throughout the experiment. Fragmentation of products through gas-phase chemistry likely also occurs but is expected to result mostly in products too volatile to be collected by TAG, and as such were not measured by this instrument.

Average $\mathrm{O} / \mathrm{C}$ based on peak area increases from 0.21 to 0.23 from TAG \#2 to TAG \#3. This increase in average $\mathrm{O} / \mathrm{C}$ and the accompanying shift in peak distribution is consistent with the trend suggested by the evolution of AMS $f_{44}$ shown in Fig. 5: that oxidation and aging continue during the period of stable aerosol concentration. Average O/C calculated using the RTC method is expected to be lower than that determined using AMS $f_{44}$ because of low response factors to oxygenated compounds. However, approximately half of the peak area as well as the largest peaks in all samples fall

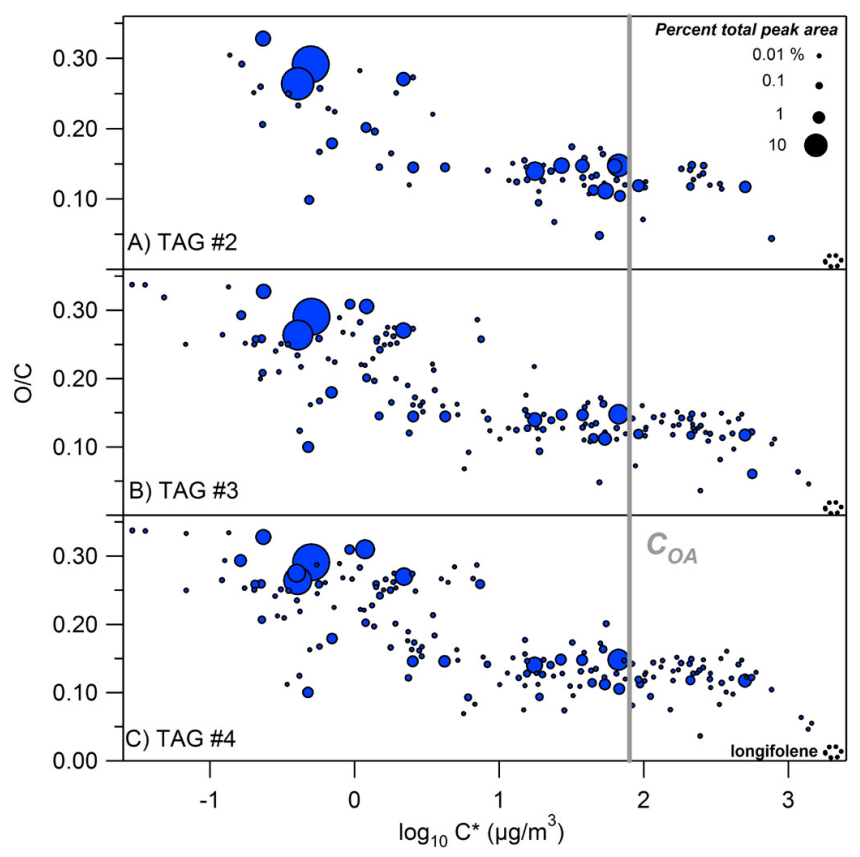

Fig. 7. Observed peaks in (A) TAG \#2, (B) TAG \#3, and (C) TAG \#4 put into the framework of the two-dimensional volatility basis set (Donahue et al., 2010). O/C and $C^{*}$ are calculated using the RTC method. Marker area is approximately proportional to percent of total peak area for each individual peak. Aerosol mass concentration is shown as the line at $\mathrm{C}_{\mathrm{OA}}$.

within the AMS $f_{44} \mathrm{O} / \mathrm{C}$ range of 0.24 to 0.30 , and average RTC O/C is only $15-25 \%$ less than estimated by AMS $f_{44}$, suggesting that $\mathrm{O} / \mathrm{C}$ values calculated using the RTC method are reasonable. In addition, the similarity between the average O/C values estimated by both RTC ( 0.21 to 0.23 ) and AMS (0.24 to 0.30$)$ supports the conclusion that 2D-TAG is indeed eluting a representative sample of the aerosol and can therefore be used to provide meaningful information about the bulk product mixture. Toward the end of the experiment, the level of oxidation appears to be relatively stable; average RTC O/C is unchanged and the number and distribution of the peaks does not change as dramatically between TAG \#3 and TAG \#4 as it did from TAG \#2 to TAG\#3, though some peaks may have dropped below detection limits as a majority of aerosol has been lost to the walls by the end of the experiment.

Though many of the observed peaks are small, the aggregated area of minor peaks accounts for a non-negligible fraction of the total observed peak area. The number of observed compounds necessary to understand the detected product mixture (Fig. 8 - shown using TAG\#3) is approximately logarithmic, with 3 peaks accounting for $50 \%$ of total peak area and 15 peaks accounting for $80 \%$ of total peak area. In other words, while 12 peaks are minor - on average each accounting for less the $3 \%$ of total peak area - together they account for nearly a third of observed peak area. Peak 
area can be thought of as a proxy for mass that eluted through the column (i.e. Ozel et al., 2010), but it is an imperfect measure as discussed above. Nevertheless, Fig. 8 suggests that the product mixture contains many significant products and likely cannot be well-described with only one or two compounds. The number of major peaks observed here is approximately of the same order as the number of first and second generation products predicted by Nguyen et al. (2009).

\section{Summary and conclusions}

A retention time correlation (RTC) method was developed to estimate $C^{*}$ volatility and degree of oxygenation $(\mathrm{O} / \mathrm{C})$ of complex mixtures from first and second dimension retention times obtained from the 2D-TAG. This method was applied to the ozonolysis of longifolene performed in a smog chamber in the presence of $1600 \mathrm{ppb}$ ozone. In this experiment, $\mathrm{O} / \mathrm{C}$ values estimated from AMS $f_{44}$ never exceed 0.30 and are in similar to those calculated using RTC, suggesting that 2D-TAG collected a representative sample of the aerosol and can therefore be used in conjunction with the AMS to provide some understanding of chemical evolution.

AMS and SMPS data show that under the conditions of these experiments, particle formation proceeded by fast, homogenous nucleation followed by slow continuous oxidation of the particle phase organics, with no further increase in aerosol mass or volume concentration after $30 \mathrm{~min}$ of ozonolysis. The continued oxidation inferred from AMS $f_{44}$ suggests that atmospheric processing is more complex than simple condensation of oxidized VOCs; either particle-phase oxidation occurs or compounds partition in and out of the particle phase while undergoing oxidation. Samples collected by 2D-TAG during the experiment show an increase in the number of less volatile, more oxygenated products with time, further supporting the conclusion that continued oxidation is not limited to simple gas phase chemistry. Because of the difficulty in definitively identifying most compounds, as well as the complexity of the potential chemistry, the possible pathways for this continued oxidation are unknown, but the increase in $f_{44}$, corroborated by increases in $\mathrm{O} / \mathrm{C}$ observed by 2D-TAG suggest it is a real phenomenon that warrants further study.

Nearly 200 peaks were observed by 2D-TAG, a small fraction of the number of potential products generated by comprehensive models (Aumont et al., 2005). The product mixture contained many non-negligible products (between 3 and 15). The major expected product of this reaction, longicamphenylone was not observed in the product mixture, though longifolenaldehyde was.

Studying the evolution of the products in the volatilitypolarity plane allows SOA precursors to be categorized not only by SOA yield, as is now common practice, but also by the product mixture volatility distribution. By using an O/C-

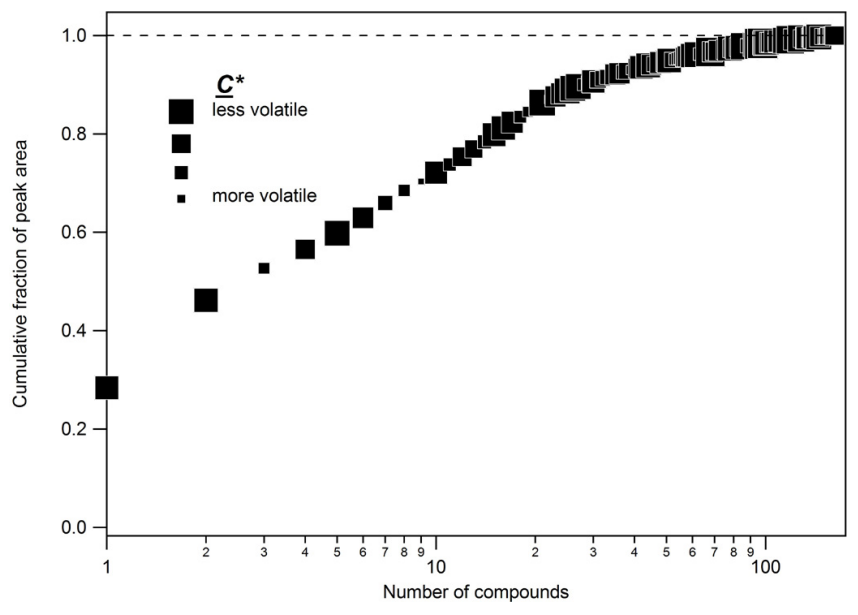

Fig. 8. Number of compounds required to account for a given fraction of total peak area. Data from the TAG \#3 sample. Marker area is approximately proportional to volatility for each individual peak.

fit as well as volatility-fit, this work allows more realistic modeling of aerosol formation using either a multi-product model or the 2D-VBS framework. Currently this method is limited to systems with levels of oxygenation lower than is observed in most ambient environments, such as sesquiterpene or monoterpene smog chamber ozonolysis; chamber experiments generate aerosol with levels of oxidation similar to semi-volatility oxygenated organic aerosol (SV-OOA), while more oxygenated low-volatility OOA (LV-OOA) is observed to be a significant factor in ambient aerosol (Jimenez et al., 2009). The study of this transition from SV-OOA to LV-OOA is consequently difficult in laboratory settings. However, 2DTAG is useful for studying the first few generations of VOC oxidation and the subsequent evolution of the OA, providing an opportunity to understand the aging and processing of SV-OOA. Analysis using the RTC method and 2D-TAG can therefore be used to inform models and improve understanding of the SV-OOA to LV-OOA transition. Future work expanding the $\mathrm{O} / \mathrm{C}$ range of gas chromatography through use of derivatizing agents may also broaden the applicability of this method for use on LV-OOA and ambient systems.

The RTC method does not yet work well for a mixture of aromatic and aliphatic compounds. Aromatic compounds are retained longer in the second dimension than aliphatic compounds of similar calculated volatility and $\mathrm{O} / \mathrm{C}$ (Worton et al., 2011) and therefore exhibit a different dependence on $t_{R}^{2}$ in these fits. This necessitates a different planar fit for each class of compounds; in order to properly apply this method, the user must know whether a compound is aliphatic or aromatic and use the appropriate calculated fit. While this is easily tractable in the case study examined here (controlled BVOC oxidation in the absence of any aromatic compounds), it does complicate the application of this method to ambient data. However, as EI spectra tend to have very different 
character for aromatic and aliphatic compounds, it is likely possible to extend the method described here to a variety of systems - even complex ambient aerosol - by including some mass spectral information.

The bimodal size distribution of the aerosol warrants further study as it may be due to the formation of SOZs. These compounds would likely be too thermally unstable to be observed by thermal desorption coupled to gas chromatography, so its presence can be neither confirmed nor denied by this study, but these data suggest a further need for novel methods of direct measurements such as those employed in this study. Direct measurements of these low volatility first generation products would greatly improve understanding of nucleation in remote forested environments.

\section{Supplementary material related to this article is available online at:

Acknowledgements. This work was supported by the US Department of Energy STTR program, DEFG02-05ER-86235 and the National Science Foundation Atmospheric Chemistry Program Grants 0922562 and 0931934. Gabriel Isaacman was funded by the US EPA Science to Achieve Results (STAR) program, FP-91781901-0.

Edited by: M. C. Facchini

\section{References}

Aiken, A. C., DeCarlo, P. F., Kroll, J. H., Worsnop, D. R., Huffman, J. A., Docherty, K. S., Ulbrich, I. M., Mohr, C., Kimmel, J. R., Sueper, D., Sun, Y., Zhang, Q., Trimborn, A. M., Northway, M., Ziemann, P. J., Canagaratna, M. R., Onasch, T. B., Alfarra, M. R., Prevot, A. S., Dommen, J., Duplissy, J., Metzger, A., Baltensperger, U., and Jimenez, J. L.: O/C and OM/OC Ratios of Primary, Secondary, and Ambient Organic Aerosols with HighResolution Time-of-Flight Aerosol Mass Spectrometry, Environ. Sci. Tech., 42, 4478-4485, 2008.

Allan, J. D., Delia, A. E., Coe, H., Bower, K. N., Alfarra, M. R., Jimenez, J. L., Middlebrook, A. M., Drewnick, F., Onasch, T. B., Canagaratna, M. R., Jayne, J. T., and Worsnop, D. R.: A generalised method for the extraction of chemically resolved mass spectra from Aerodyne aerosol mass spectrometer data, J. Aerosol Sci., 35, 909-922, 2004.

Atkinson, R. and Arey, J.: Atmospheric degradation of volatile organic compounds, Chem. Rev., 103, 4605-4638, 2003.

Aumont, B., Szopa, S., and Madronich, S.: Modelling the evolution of organic carbon during its gas-phase tropospheric oxidation: development of an explicit model based on a self generating approach, Atmos. Chem. Phys., 5, 2497-2517, doi:10.5194/acp-52497-2005, 2005.

Barsanti, K. C. and Pankow, J. F.: Thermodynamics of the formation of atmospheric organic particulate matter by accretion reactions - Part 1: aldehydes and ketones, Atmos. Environ., 38, 4371-4382, 2004.
Bonn, B. and Moorgat, G. K.: New particle formation during $\alpha$ and $\beta$-pinene oxidation by $\mathrm{O}_{3}, \mathrm{OH}$ and $\mathrm{NO}_{3}$, and the influence of water vapour: particle size distribution studies, Atmos. Chem. Phys., 2, 183-196, doi:10.5194/acp-2-183-2002, 2002.

Bonn, B. and Moortgat, G. K.: Sesquiterpene ozonolysis: Origin of atmospheric new particle formation from biogenic hydrocarbons, Geophys. Res. Lett., 30, 1585, doi:10.1029/2003GL017000, 2003.

Bonn, B., Schuster, G., and Moortgat, G. K.: Influence of Water Vapor on the Process of New Particle Formation during Monoterpene Ozonolysis, J. Phys. Chem. A, 106, 2869-2881, 2002.

Bouvier-Brown, N. C., Goldstein, A. H., Gilman, J. B., Kuster, W. C., and de Gouw, J. A.: In-situ ambient quantification of monoterpenes, sesquiterpenes, and related oxygenated compounds during BEARPEX 2007: implications for gas- and particle-phase chemistry, Atmos. Chem. Phys., 9, 5505-5518, doi:10.5194/acp-9-5505-2009, 2009.

Chuong, B., Zhang, J., and Donahue, N. M.: Cycloalkene ozonolysis: collisionally mediated mechanistic branching, J. Am. Chem. Soc., 126, 12363-73, 2004.

Claeys, M., Iinuma, Y., Szmigielski, R., Surratt, J. D., Blockhuys, F., van Alsenoy, C., Boge, O., Sierau, B., Gomez-Gonzalez, Y., Vermeylen, R., van Der Veken, P., Shahgholi, M., Chan, A. W., Herrmann, H., Seinfeld, J. H., and Maenhaut, W.: Terpenylic Acid and Related Compounds from the Oxidation of $r-$ Pinene: Implications for New Particle Formation and Growth above Forests, Environ. Sci. Tech., 43(18), 6976-6982, 2009.

Donahue, N. M., Huff Hartz, K. E., Chuong, B., Presto, A. A., Stanier, C. O., Rosenhørn, T., Robinson, A. L., and Pandis, S. N.: Critical factors determining the variation in SOA yields from terpene ozonolysis: A combined experimental and computational study, Faraday Discuss., 130, 295-309, 2005.

Donahue, N. M., Robinson, A. L., Stanier, C. O., and Pandis, S. N.: Coupled partitioning, dilution, and chemical aging of semivolatile organics, Environ. Sci. Tech., 40, 2635-43, 2006.

Donahue, N. M., Tischuk, J. E., Marquis, B. J., and Huff Hartz, K. E.: Secondary organic aerosol from limona ketone: insights into terpene ozonolysis via synthesis of key intermediates, Phys. Chem. Chem. Phys., 9, 2991-2998, 2007.

Donahue, N. M., Epstein, S. A., Pandis, S. N., and Robinson, A. L.: A two-dimensional volatility basis set: 1. organic-aerosol mixing thermodynamics, Atmos. Chem. Phys., 11, 3303-3318, doi:10.5194/acp-11-3303-2011, 2011.

Gao, S., Keywood, M., Ng, N. L., Surratt, J., Varutbangkul, V., Bahreini, R., Flagan, R. C., and Seinfeld, J. H.: LowMolecular-Weight and Oligomeric Components in Secondary Organic Aerosol from the Ozonolysis of Cycloalkenes and $\alpha$ Pinene, J. Phys. Chem. A, 108, 10147-10164, 2004.

Goldstein, A. H. and Galbally, I.: Known and unexplored organic constituents in the earth's atmosphere, Environ. Sci. Tech., 41, 1514-1521, 2007.

Goldstein, A. H., Worton, D. R., Williams, B. J., Hering, S. V., Kreisberg, N. M., Paniæ, O., and Górecki, T.: Thermal desorption aerosol comprehensive two-dimensional gas chromatographic resolution for in-situ measurements of organic aerosols, J. Chrom. A, 1186, 340-347, 2008.

Guenther, A., Hewitt, C. N., Erickson, D., Fall, R., Geron, C., Graedel, T., Harley, P., Klinger, L., Lerdau, M., Mckay, W. A., Pierce, T., Scholes, B., Steinbrecher, R., Tallamraju, R., Tay- 
lor, J., and Zimmerman, P.: A global model of natural volatile organic compound emissions, J. Geophys. Res.-Atmos., 100, 8873-8892, 1995.

Hallquist, M., Wenger, J. C., Baltensperger, U., Rudich, Y., Simpson, D., Claeys, M., Dommen, J., Donahue, N. M., George, C., Goldstein, A. H., Hamilton, J. F., Herrmann, H., Hoffmann, T., Iinuma, Y., Jang, M., Jenkin, M. E., Jimenez, J. L., Kiendler-Scharr, A., Maenhaut, W., McFiggans, G., Mentel, Th. F., Monod, A., Prévôt, A. S. H., Seinfeld, J. H., Surratt, J. D., Szmigielski, R., and Wildt, J.: The formation, properties and impact of secondary organic aerosol: current and emerging issues, Atmos. Chem. Phys., 9, 5155-5236, doi:10.5194/acp-95155-2009, 2009.

Hinckley, D. A., Bidleman, T. F., Foreman, W. T., and Tuschall, J. R.: Determination of vapor pressures for nonpolar and semipolar organic compounds from gas chromatograhic retention data, J. Chem. Eng. Data, 35, 232-237, 1990.

Intergovernmental Panel on Climate Change: A report of Working Group I of the Intergovernmental Panel on Climate Change, 2007.

Jaoui, M., Edney, E. O., Kleindienst, T. E., Lewandowski, M., Offenberg, J. H., Surratt, J. D., and Seinfeld, J. H.: Formation of secondary organic aerosol from irradiated a-pinene/toluene/NOx mixtures and the effect of isoprene and sulfur dioxide, J. Geophys. Res., 113, D09303, doi:10.1029/2007JD009426, 2008.

Jensen, D. J. and Schall, E. D.: Determination of Vapor Pressures of Some Phenoxyacetic Herbicides by Gas-Liquid Chromatography, J. Agric. Food Chem., 14, 123-126, 1966.

Jimenez, J. L., Canagaratna, M. R., Donahue, N. M., Prevot, A. S., Zhang, Q., Kroll, J. H., DeCarlo, P. F., Allan, J. D., Coe, H., Ng, N. L., Aiken, A. C., Docherty, K. S., Ulbrich, I. M., Grieshop, A. P., Robinson, A. L., Duplissy, J., Smith, J. D., Wilson, K. R., Lanz, V. A., Hueglin, C., Sun, Y. L., Tian, J., Laaksonen, A., Raatikainen, T., Rautiainen, J., Vaattovaara, P., Ehn, M., Kulmala, M., Tomlinson, J. M., Collins, D. R., Cubison, M. J., Dunlea, E. J., Huffman, J. A., Onasch, T. B., Alfarra, M. R., Williams, P. I., Bower, K., Kondo, Y., Schneider, J., Drewnick, F., Borrmann, S., Weimer, S., Demerjian, K., Salcedo, D., Cottrell, L., Griffin, R. J., Takami, A., Miyoshi, T., Hatakeyama, S., Shimono, A., Sun, J. Y., Zhang, Y. M., Dzepina, K., Kimmel, J. R., Sueper, D., Jayne, J. T., Herndon, S. C., Trimborn, A. M., Williams, L. R., Wood, E. C., Middlebrook, A. M., Kolb, C. E., Baltensperger, U., and Worsnop, D. R.: Evolution of Organic Aerosols in the Atmosphere, Science, 326, 1525-1529, 2009.

Kanakidou, M., Seinfeld, J. H., Pandis, S. N., Barnes, I., Dentener, F. J., Facchini, M. C., Van Dingenen, R., Ervens, B., Nenes, A., Nielsen, C. J., Swietlicki, E., Putaud, J. P., Balkanski, Y., Fuzzi, S., Horth, J., Moortgat, G. K., Winterhalter, R., Myhre, C. E., Tsigaridis, K., Vignati, E., Stephanou, E. G., and Wilson, J.: Organic aerosol and global climate modelling: a review, Atmos. Chem. Phys., 5, 1053-1123, 2005,

http://www.atmos-chem-phys.net/5/1053/2005/.

Kroll, J. H. and Seinfeld, J. H.: Chemistry of secondary organic aerosol: Formation and evolution of low-volatility organics in the atmosphere, Atmos. Environ., 42, 3593-3624, 2008.

Lee, A., Goldstein, A. H., Keywood, M. D., Gao, S., Varutbangkul, V., Bahreini, R., Ng, N. L., Flagan, R. C., and Seinfeld, J. H.: Gas-Phase Products and Secondary Aerosol Yields from the Ozonolysis of Ten Different Terpenes, J. Geophys. Res., 111,
D07302, doi:10.1029/2005JD006437, 2006a.

Lee, A., Goldstein, A. H., Kroll, J. H., Ng, N. L., Varutbangkul, V., Flagan, R. C., and Seinfeld, J. H.: Gas-Phase Products and Secondary Aerosol Yields from the Photooxidation of 16 Different Terpenes, J. Geophys. Res., 111, D17305, doi:10.1029/2006JD007050, 2006b.

Lyman, W. J.: Environmental Exposure From Chemicals. Volume 1, CRC Press, Inc., Boca Raton, FL, 1985.

Maksymiuk, C. S., Gayahtri, C., Gil, R. R., and Donahue, N. M.: Secondary organic aerosol formation from multiphase oxidation of limonene by ozone: mechanistic constraints via twodimensional heteronuclear NMR spectroscopy, Phys. Chem. Chem. Phys., 11, 7810-7818, 2009.

Ng, N. L., Chhabra, P. S., Chan, A. W. H., Surratt, J. D., Kroll, J. H., Kwan, A. J., McCabe, D. C., Wennberg, P. O., Sorooshian, A., Murphy, S. M., Dalleska, N. F., Flagan, R. C., and Seinfeld, J. H.: Effect of $\mathrm{NO}_{\mathrm{x}}$ level on secondary organic aerosol (SOA) formation from the photooxidation of terpenes, Atmos. Chem. Phys., 7, 5159-5174, doi:10.5194/acp-7-5159-2007, 2007.

Nguyen, T. L., Peeters, J., and Vereecken, L.: Theoretical study of the gas-phase ozonolysis of $\beta$-pinene (C10H16), Phys. Chem. Chem. Phys., 11, 5643-5656, 2009.

Odum, J. R., Hoffmann, T., Bowman, F., Collins, D. R., Flagan, R. C., and Seinfeld, J. H.: Gas/particle partitioning and secondary organic aerosol yields, Environ. Sci. Tech., 30, 2580-2585, 1996.

Ormeño, E., Gentner, D. R., Fares, S., Karlik, J., Park, J. H., and Goldstein, A. H.: Sesquiterpenoid emissions from agricultural crops: correlations to monoterpenoid emissions and leaf terpene content, Environ. Sci. Tech., 44, 3758-3764, 2010.

Ozel, M., Ward, M., Hamilton, J., Lewis, A., Raventos-Duran, T., and Harrison, R.: Analysis of Organic Nitrogen Compounds in Urban Aerosol Samples Using GCxGC-TOF/MS, Aerosol Sci. Tech., 44, 109-116, 2010.

Pankow, J. F.: An absorption model of gas/particle partitioning of organic compounds in the atmosphere, Atmos. Environ., 28, 185-188, 1994.

Pankow, J. F. and Asher, W. E.: SIMPOL.1: a simple group contribution method for predicting vapor pressures and enthalpies of vaporization of multifunctional organic compounds, Atmos. Chem. Phys., 8, 2773-2796, doi:10.5194/acp-8-27732008, 2008.

Pankow, J. F. and Barsanti, K. C.: The carbon number-polarity grid: A means to manage the complexity of the mix of organic compounds when modeling atmospheric organic particulate matter, Atmos. Environ., 43, 2829-2835, 2009.

Pathak, R. K., Stanier, C. O., Donahue, N. M., and Pandis, S. N. Ozonolysis of a-pinene at atmospherically relevant concentrations: Temperature dependence of aerosol mass fractions (yields), J. Geophys. Res., 112, D03201, doi:10.1029/2006JD007436, 2007.

Pierce, J. R., Engelhart, G. J., Hildebrandt, L., Weitkamp, E. A., Pathak, R. K., Donahue, N. M., Robinson, A. L., Adams, P. J., and Pandis, S. N.: Constraining Particle Evolution from Wall Losses, Coagulation, and Condensation-Evaporation in SmogChamber Experiments: Optimal Estimation Based on Size Distribution Measurements, Aerosol Sci. Tech., 42, 1001-1015, 2008.

Pope, C. A. and Dockery, D. W.: Health effects of fine particulate air pollution: Lines that connect, J. Air Waste Manage., 56, 709- 
$742,2006$.

Shu, Y. and Atkinson, R.: Rate constants for the gas-phase reactions of $\mathrm{O}_{3}$ with a series of Terpenes and $\mathrm{OH}$ radical formation from the $\mathrm{O}_{3}$ reactions with Sesquiterpenes at $296 \pm 2 \mathrm{~K}$, Int. J. Chem. Kin., 26, 1193-1205, 1994.

Surratt, J. D., Go, Y., Chan, A. W., Vermeylen, R., Shahgholi, M., Kleindienst, T. E., Edney, E. O., Offenberg, J. H., Lewandowski, M., Jaoui, M., Maenhaut, W., Claeys, M., Flagan, R. C., and Seinfeld, J. H.: Organosulfate Formation in Biogenic Secondary Organic Aerosol, J. Phys. Chem. A, 112, 8345-8378, 2008.

US Environmental Protection Agency: Estimation Program Interface (EPI) Suite, 2008.

Weitkamp, E. A., Sage, A. M., Pierce, J. R., Donahue, N. M., and Robinson, A. L.: Organic aerosol formation from oxidation of diesel exhaust in a smog chamber, Environ. Sci. Tech., 41, 69696975, 2007.

Williams, B. J., Goldstein, A. H., Kreisberg, N. M., and Hering, S. V.: An In-Situ Instrument for Speciated Organic Composition of Atmospheric Aerosols: Thermal Desorption Aerosol GC/MSFID (TAG), Aerosol Sci. Tech., 40, 627-638, 2006.

Williams, B. J., Goldstein, A. H., Kreisberg, N. M., and Hering, S. V.: In situ measurements of gas/particle-phase transitions for atmospheric semivolatile organic compounds, P. Natl. Acad. Sci. USA, 107, 6676-6681, 2010a.

Williams, B. J., Goldstein, A. H., Kreisberg, N. M., Hering, S. V., Worsnop, D. R., Ulbrich, I. M., Docherty, K. S., and Jimenez, J. L.: Major components of atmospheric organic aerosol in southern California as determined by hourly measurements of source marker compounds, Atmos. Chem. Phys., 10, 11577-11603, doi:10.5194/acp-10-11577-2010, 2010.
Winterhalter, R., Neeb, P., Grossmann, D., Kolloff, A., Horie, O., and Moortgat, G. K.: Products and Mechanism of the Gas Phase Reaction of Ozone with $\beta$-Pinene, J. Atmos. Chem., 35, 165 197, 2000.

Winterhalter, R., Herrmann, F., Kanawati, B., Nguyen, T. L., Peeters, J., Vereecken, L., and Moortgat, G. K.: The gas-phase ozonolysis of beta-caryophyllene $(\mathrm{C}(15) \mathrm{H}(24))$. Part I: an experimental study, Phys. Chem. Chem. Phys., 11, 4152-72, 2009.

Worton, D. R., Kreisberg, N. M., Isaacman, G., Teng, A. P., McNeish, C., Górecki, T., Hering, S. V., and Goldstein, A. H.: Thermal desorption comprehensive multi-dimensional gas chromatography: An improved instrument for in-situ measurements of organic aerosols, Aerosol Sci. Tech., in review, 2011.

Zhang, J., Huff Hartz, K. E., Pandis, S. N., and Donahue, N. M.: Secondary organic aerosol formation from limonene ozonolysis: homogeneous and heterogeneous influences as a function of $\mathrm{NO}_{(\mathrm{x})}$, J. Phys. Chem. A, 110, 11053-11063, 2006.

Zhang, Q., Jimenez, J. L., Canagaratna, M. R., Allan, J. D., Coe, H., Ulbrich, I. M., Alfarra, M. R., Takami, A., Middlebrook, A. M., Sun, Y. L., Dzepina, K., Dunlea, E. J., Docherty, K. S., DeCarlo, P. F., Salcedo, D., Onasch, T. B., Jayne, J. T., Miyoshi, T., Shimono, A., Hatakeyama, S., Takegawa, N., Kondo, Y., Schneider, J., Drewnick, F., Borrmann, S., Weimer, S., Demerjian, K., Williams, P., Bower, K., Bahreini, R., Cottrell, L., Griffin, R. J., Rautiainen, J., Sun, J. Y., Zhang, Y. M., and Worsnop, D. R.: Ubiquity and dominance of oxygenated species in organic aerosols in anthropogenically-influenced Northern Hemisphere midlatitudes, Geophys. Res. Lett., 34, L13801, doi:10.1029/2007GL029979, 2007. 